\title{
BMJ Open Prevalence, duration of exposure and predicting factors for snus use among young Finnish men: a cross- sectional study
}

\author{
Maria Danielsson (D) , ${ }^{1,2}$ Tarja Tanner, ${ }^{3,4}$ Pertti Patinen, ${ }^{1}$ Dowen Birkhed, ${ }^{5}$ \\ Vuokko Anttonen, ${ }^{3,4}$ Anelma Lammi, ${ }^{6}$ Simo Siitonen, ${ }^{7}$ Jukka Ollgren, ${ }^{8}$ \\ Liisa Pylkkänen, ${ }^{9,10}$ Tuula Vasankari ${ }^{6,11}$
}

To cite: Danielsson M, Tanner T, Patinen $\mathrm{P}$, et al. Prevalence, duration of exposure and predicting factors for snus use among young Finnish men: a cross-sectional study. BMJ Open 2021;11:e050502. doi:10.1136/ bmjopen-2021-050502

- Prepublication history for this paper is available online. To view these files, please visit the journal online (http://dx.doi org/10.1136/bmjopen-2021050502).

$\mathrm{MD}$ and $\mathrm{TT}$ contributed equally

Received 02 March 2021 Accepted 31 August 2021

Check for updates

(c) Author(s) (or their employer(s)) 2021. Re-use permitted under CC BY-NC. No commercial re-use. See rights and permissions. Published by BMJ.

For numbered affiliations see end of article.

Correspondence to

Maria Danielsson;

maria.danielsson@helsinki.fi

\section{ABSTRACT}

Objective The health hazards of tobacco products depend on the level of exposure, but little is known about the characteristics of snus use. The aim of this study was to investigate the duration of daily exposure to snus among occasional and daily users and its associated predictive factors among young Finnish men.

Design Cross-sectional questionnaire study. Setting Three out of 16 Finnish Defence Forces units. Participants 1280 young Finnish male conscripts starting their military service in 2016 chosen by simple random sampling.

Primary and secondary measures The prevalence, duration of use and the amount of daily usage of snus and cigarettes were investigated. The attitudes towards perceived harmfulness of snus and the predictive factors affecting the total time of snus consumption were examined.

Results Almost a fifth (19.5\%) of the conscripts reported daily snus use, and a further $16 \%$ reported occasional use. Daily snus use was associated with an earlier starting age, longer duration of use and higher daily exposure time compared with occasional use. On average, daily snus users consumed 10 portions and occasional users three portions per day $(p<0.001)$. The daily total exposure time for daily users was $372 \mathrm{~min}(95 \% \mathrm{Cl} 344$ to 401$)$ and for occasional users $139 \mathrm{~min}(95 \% \mathrm{Cl} 106$ to 171). Respondents with an upper secondary education had significantly less daily total exposure than those with basic comprehensive education $(p=0.036)$. Perceptions of snus as a harmful substance resulted in a significantly lower duration of exposure.

Conclusion Snus use was very common among young Finnish men. High snus exposure duration was associated with an earlier starting age, a longer history of use and a careless attitude to its health hazards. A higher education level was a protective factor for total exposure time. Studies of the long-term health effects and dependency profile of snus use are needed.

\section{INTRODUCTION}

The prevalence of smoking has decreased in developed countries in the last decades. However, alternative tobacco and nicotine
Strengths and limitations of this study

- The large study sample (10\% of all Finnish conscripts in the year 2016) allowed us to investigate the prevalence of tobacco and smokeless tobacco use among young Finnish male adults.

The high response rate (54\%) increased the reliability of the study results.

- This article fills up the gap in the prevalence of smokeless tobacco (snus) use by showing the amount of daily and occasional use, total exposure time and protective factors for snus use.

- The survey included female respondents but as their proportion among all respondents was very small $(3 \%)$, they were excluded from the analyses.

- Previous studies have shown that self-reports (as applied in this study) tend to underestimate smoking status, frequency and amounts used.

products have been launched as a means of harm reduction, ${ }^{1}$ but the health problems associated with nicotine and other chemical compounds remain. ${ }^{23}$ As a result, the use of typically conveniently portion-packed Swedish type of moist smokeless tobacco called snus has increased in Europe, particularly in the Nordic countries. ${ }^{4-9}$ In addition, a similar trend has been observed in the USA during the last decade among younger generations. ${ }^{10-13}$

The marketing of snus is banned in all European Union countries except Sweden. In Finland, consumers are allowed to bring a limited amount of snus from abroad for personal use. However, illegal snus trade is common. ${ }^{1415}$

A trend of increasing snus use has been seen among both genders, although snus use is still the most common among young males. ${ }^{6}$ A recent study showed that up to $33 \%$ of young Finnish men, aged between 
18 and 29 years, used snus, and $14 \%$ used it daily. ${ }^{4}$ Around 22\% of 16-29 year-old men in Sweden use snus, and $16 \%$ of men in this age group use it regularly. ${ }^{16}$ A slightly higher prevalence of snus use has recently been reported in Norway among 16-24 year-old men, of whom $33 \%$ use snus, $26 \%$ regularly. ${ }^{717}$ According to the National Survey on Drug Use and Health conducted in the USA in 2016, around $18 \%$ of respondents aged between 18 and 25 years had used any type of smokeless tobacco during their lifetime, and $8 \%$ had used it during the last year. ${ }^{18}$

As the ingredients of different smokeless tobacco products vary, health hazards also vary considerably. The Swedish type of moist snus has been promoted as a safer and less toxic and carcinogenic substance due to a voluntary quality standard. However, the high level of unprotonated nicotine and high $\mathrm{pH}$ value typically found in the Swedish type of snus enhance nicotine absorption and increase bioavailability. ${ }^{2}{ }^{19}$ Snus is usually placed in the sulcus under the upper lip in close contact with the oral mucosa, where nicotine and other chemicals are absorbed efficiently through the mucosal membrane to the systemic circulation, resulting in a high nicotine intake. ${ }^{90-22}$

Tobacco studies regarding smoking have shown that nicotine dependency and morbidity are related to the total amount and duration of nicotine intake. ${ }^{23-25}$ Similar studies concerning snus are scarce. Several studies indicate high levels of nicotine or the metabolite cotinine among smokeless tobacco and snus users, which may increase the addictiveness of the product and elevate the risk of a disadvantageous effect on health. ${ }^{21922}{ }^{26}$ However, there is considerable variation in the nicotine metabolism between individuals. ${ }^{20} 27$

Snus use has previously been marginal outside the Nordic countries, and limited data are available concerning long-term adverse health outcomes. However, we know that nicotine has several harmful effects on health ${ }^{27}$; snus use has been associated with cardiovascular and gastrointestinal diseases, impaired or strained blood circulation, type 2 diabetes, prostate and gastrointestinal cancer, and negative impacts on reproductive health. ${ }^{28-38}$ In addition, the severity of leucoplakia lesions in oral mucosa increases with the duration of snus use. ${ }^{9}$ Snus is likely to cause strong nicotine addiction, even after shortterm use. ${ }^{2439}$

Data concerning daily total exposure to snus are scarce and often linked to tobacco companies. Digard et $a t^{40}$ observed that the average use time for one snus portion among Swedish men was around 1 hour, and the total time of daily use was 13.0 hours. Later, in 2013, Digard $e t$ $a t^{41}$ concluded that the duration of use was an important variable to take into account because the absorption of nicotine continued during the whole exposure time.

The aim of this study was to quantify and characterise the mean daily exposure time of snus and investigate predictive factors affecting snus use among young Finnish males.

\section{MATERIAL AND METHODS}

The methodology has previously been described by Danielsson $e t$ al. $^{4}$ The study was conducted among young males, aged 18-29 years, starting their military service. Three out of 16 Finnish Defence Forces units, the Guard Jaeger Regiment, the Karelian Brigade and the Kainuu Brigade, were chosen because they train recruits from different parts of Finland. The troops were selected by simple random sampling.

\section{Sampling}

The study population consisted of 2355 conscripts chosen by simple random sampling, covering both annual cohorts entering military service in January and June 2016. A total of 1280 males responded to the questionnaire, a response rate of $54.4 \%$. Women $(n=34,2.6 \%)$ were excluded from the analyses due to the low number of female conscripts. Only respondents giving their informed consent were included in the study.

\section{Data collection and measurement}

The conscripts received a questionnaire-based survey during their first week of service concurrently with the general health inspection. The following questions were used in the present study: how old are you (years)?; What is your gender (male or female)?; What is your level of education (comprehensive school, vocational school and upper secondary school)?; Do you currently smoke (daily, occasionally, formerly and never)?; Do you currently use snus (daily, occasionally, formerly and never)?; How long have you smoked/used snus (years)?; At what age did you start using snus (years)?; How many portions do you use on days when you use snus?; How long do you keep the snus portion in your mouth (<30 min, 30-59 min, $\geq 1$ hour, $\geq 2$ hours, $\geq 3$ hours)?; and How harmful to your health do you perceive smoking/snus use to be (not at all, hardly, neither good nor bad, harmful and very harmful)?

\section{Statistical analyses}

The history (duration) of snus use was calculated from the conscript's age and reported age at which they started the use. The mean daily exposure time to snus was calculated by multiplying the mean number of daily portions by the lower and upper limits of the daily categorised use time (0-30, 31-60, 61-120 and 121+ min). The question assessing the age at which regular tobacco use started was limited to respondents starting from 9 years old.

Complete case analysis, which excludes participants with any missing data, was used in cross-tabulation calculations to address the missing data. Complete case analysis can lead to bias and power loss. Therefore, we also used multiple imputation by chained equations in regression models to study the stability of the models regarding the missingness. ${ }^{42}$

Cross-tabulation and $\chi^{2}$ tests were used in analyses. For statistical analyses, median and linear-by-linear association tests with Spearman's rho correlation or gamma coefficient test were used. An interval regression model was 
fitted in the analysis as the outcome variable was interval censored.

All analyses were performed using the SPSS software (V.23.0, SPSS, Inc, Chicago, Illinois, USA) and Stata (V.16.1) statistical software for data science).

\section{Patient and public involvement}

Patients or the public were not involved in this research.

\section{RESULTS}

\section{Prevalence of snus and cigarette use}

The mean age of the respondents was 19.5 ( $\mathrm{SD} \pm 1.3$ ) years, with a range of $18-29$ years. Almost a fifth (20\%, $\mathrm{n}=246 / 1264)$ of the conscripts reported daily snus use, and a further $16 \%(\mathrm{n}=204 / 1264)$ used snus occasionally, resulting in a total of $36 \%(n=450 / 1264)$ snus users. The corresponding figures for the prevalence of smoking were $22 \%(n=273 / 1266)$ and $13 \%(n=169)$; that is, a total of $35 \% \quad(n=442 / 1266)$ were smokers. Approximately $20 \%$ $(n=252 / 1267)$ of the respondents were dual users of snus and cigarettes at least occasionally. A third (27/79) of previous snus users had shifted to daily smoking and $40 \%$ (54/136) of former smokers had become daily snus users. The survey inquired about the use of electronic cigarettes, but this was not evaluated due to the low number of users $(2.6 \%)$.

The correlation between educational level and smoking was strong (gamma $=0.6$, linear by linear: $\mathrm{p}<0.001$ ). Moreover, only $6 \%$ of respondents with an upper secondary education smoked $(n=39 / 640)$, whereas a little more than a third of the respondents with vocational education $(n=182 / 524)$ and half of the respondents with only basic comprehensive education $(n=52 / 102)$ smoked daily. The correlation was less evident among snus users (gamma $=0.2$, linear by linear: $\mathrm{p}=0.822$ ). Roughly a fifth of the respondents in all three groups used snus daily. Dual use of snus and cigarettes was most common among respondents with vocational and comprehensive educational background (linear-by-linear test: $\mathrm{p}<0.001$ ) (table 1).
Starting age, duration of use and amount of daily use according to tobacco habits

There was a notable difference between daily and occasional snus users concerning the starting age, duration of use and the total number of snus portions and cigarettes used; the median age of starting snus use was 16 among daily users and 17 among occasional users $(p<0.001)$. Daily users used on average 10 portions per day, but occasional users used only a third of this amount (median 10 portions vs 3 portions, $\mathrm{p}<0.001$ ). The median duration of snus use was 3 years among daily users and 2 years among occasional users $(\mathrm{p}<0.001)$ (table 2$)$.

Daily smokers also had a longer history of cigarette use than occasional smokers. The median starting ages were 15 and 17 , respectively $(\mathrm{p}<0.001)$, and they had smoked nearly 2 years longer than occasional smokers (median 5 years vs 3 years $)(p<0.001)$. The median amount of cigarettes smoked per day was 10 among daily smokers and one among occasional smokers $(\mathrm{p}<0.001)$ (table 2$)$.

\section{Exposure time per snus portion}

On average, daily snus users kept the snus portions longer in the oral cavity than occasional users. Only a third $(30 \%, \mathrm{n}=64 / 213)$ of daily users kept it in the mouth for 30 min or less, and the rest $(61 \%, n=129 / 213)$ kept it for between 30 and $60 \mathrm{~min}$. A little more than half $(52 \%$, $\mathrm{n}=86 / 164)$ of occasional users kept the snus in the mouth for a maximum of $30 \mathrm{~min}$, and $43 \%(\mathrm{n}=70 / 164)$ kept it in the mouth between 30 and $60 \mathrm{~min}$. The difference between daily and occasional users in relation to exposure time was significant $(\mathrm{p}<0.001)$ (table 3$)$. There was a mild monotonic increasing correlation between snus portions and the time kept in the mouth (Spearman's rho $0.4, \mathrm{p}<0001)$.

\section{Mean daily total exposure time to snus}

The mean time of daily exposure to snus was high, being 6 hours and 12 min per day among daily users. For occasional users' the subsequent mean use time was 2 hours and 19 min per day on the days when snus was used (table 3).

Table 1 The prevalence of smoking and snus use by education

\begin{tabular}{|c|c|c|c|c|c|c|c|}
\hline & \multicolumn{3}{|c|}{ Snus*, $n=1264$} & \multicolumn{3}{|c|}{ Cigarettes $†, n=1266$} & \multirow[t]{2}{*}{$\begin{array}{l}\text { Dual use } \neq \text {, } \\
n=1267\end{array}$} \\
\hline & Daily & Occasional & Non-users & Daily & Occasional & Non-users & \\
\hline Comprehensive school, n (\%) & $23(22.6)$ & $30(29.4)$ & 49 (48.0) & $52(51.0)$ & $14(13.7)$ & $36(35.3)$ & 35 (34.3) \\
\hline Vocational school, n (\%) & $112(21.5)$ & $106(20.4)$ & $303(58.1)$ & $182(34.7)$ & $72(13.7)$ & $270(51.5)$ & $131(25.2)$ \\
\hline
\end{tabular}

*Gamma $=0.2$, linear-by-linear association test $p=0.822$ (missing values $0.8 \%$ ).

†Gamma $=0.6$, linear-by-linear association test $p<0.001$ (missing values $0.6 \%$ ).

$\ddagger$ Daily and occasional use, linear-by-linear association test $p<0.001$ (missing values $1.0 \%$ ). 


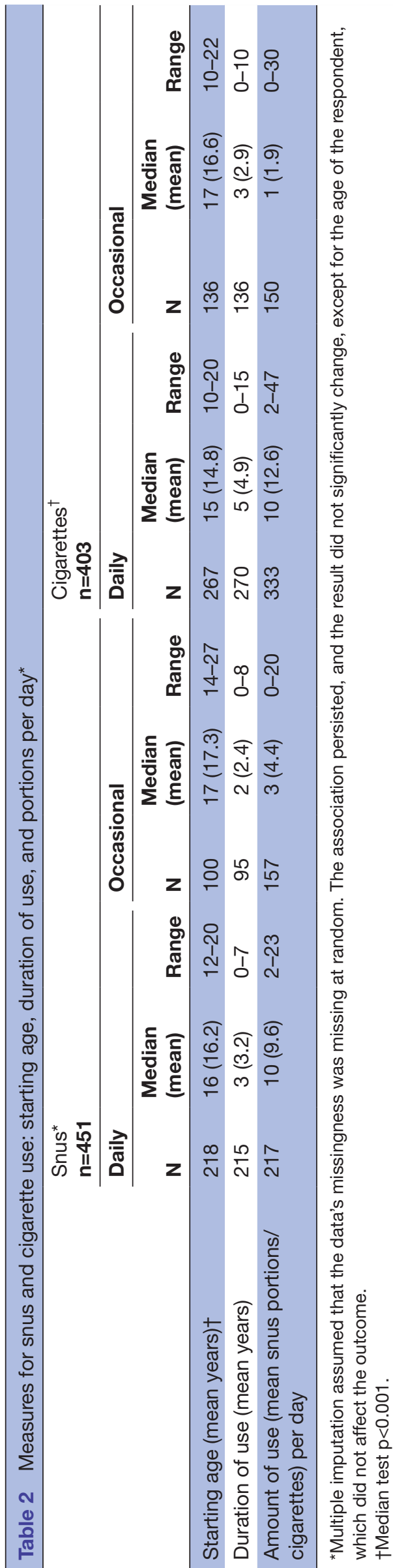

Table 3 Total daily exposure time to snus in relation to use status $\left(n=271^{*}\right)$

\begin{tabular}{lll}
\hline & $\begin{array}{l}\text { Minutes } \\
\text { (hours)/day }\end{array}$ & $\mathbf{9 5 \%} \mathbf{~ C l ~ i n ~ m i n ~}$ \\
\hline Daily snus use & $372(6.2)$ & 344 to 401 \\
Occasional snus use & $139(2.3)$ & 106 to 171 \\
$\begin{array}{l}\text { Former use } \dagger \\
\begin{array}{l}\text { Never used/used } \\
\text { regularly }\end{array}\end{array}$ & $142(2.4)$ & 51.8 to 232.2 \\
\hline
\end{tabular}

*Answer for questions: the number of snus portions used per day and the average using time per one portion. Total exposure time to snus=snus portions/day $\times$ the time in minutes that the snus portion was kept in the mouth.

†Previous snus use, recently quitted. $\$ 3.2 \%$ (24/740) used 1-5 portions/day even when reporting themselves never users, and the rest reported 0 portions.

\section{Predictive factors for the daily total exposure time to snus}

The daily total exposure time to snus was strongly correlated with the duration of snus use; each additional year of use increased the mean total exposure time by three-quarters of an hour per day $(p<0.001)$. Snus use decreased by 25 min per day with each additional year of the respondent's age. Respondents with an upper secondary education had a significantly shorter total exposure time to snus $(-141 \mathrm{~min})$ than those with basic comprehensive education $(\mathrm{p}=0.036)$. The association for respondents with a vocational education was not as significant but still detectable $(-36 \mathrm{~min}, \mathrm{p}=0.556)$ when the results were adjusted for age and history of tobacco use.

Occasional smoking increased the total exposure time to snus by more than an hour per day $(\mathrm{p}=0.054)$. However, daily smokers were less likely to use snus than those who had never smoked $(\mathrm{p}=0.033)$. Interestingly, the total exposure time to snus was associated with the perceived harmfulness of snus use; the exposure time was lower among respondents who recognised snus as a harmful substance $(-85 \mathrm{~min}, \mathrm{p}=0.025)$ (table 4$)$.

\section{DISCUSSION}

Our study showed that daily snus users started snus use an average of 1 year earlier, at the age of 16 years, used triple the amount of snus ( 10 portions per day) and kept snus in their mouth more than 6 hours per day, almost triple that of occasional users. Furthermore, snus use was less common among older respondents. The prevalence of exclusive snus and cigarette use was almost equal, at about $35 \%$ each. Occasional smokers were more likely to use snus than daily smokers. Respondents with an upper secondary education had a significantly shorter total exposure time to snus than those with only a comprehensive education, even though the prevalence of daily snus use showed little difference. The association for respondents with a vocational education 
Table 4 Linear regression analysis of factors affecting the total time of snus use per day

\begin{tabular}{|c|c|c|c|}
\hline Predictive factor & $\begin{array}{l}\text { Effect of daily total } \\
\text { exposure time in min } \\
\text { (hours) }\end{array}$ & $95 \% \mathrm{Cl}$ in $\min$ & P value* \\
\hline Age of respondent $\ddagger$ & $-25(-0.4)$ & -47 to -3 & 0.026 \\
\hline Comprehensive school (reference) & 0 & & \\
\hline Never regularly smoked (reference) & 0 & & \\
\hline Daily smoker & $-78(-1.3)$ & -150 to -6 & 0.033 \\
\hline Occasional smoker & $72(1.2)$ & -1 to 145 & 0.054 \\
\hline Former smoker & $45(0.75)$ & -26 to 117 & 0.211 \\
\hline
\end{tabular}

The number of participants: $n=308$. Negative effect in minutes refers to factors decreasing the total use time. Positive effect in minutes refers to factors increasing it compared with the reference $(0 \mathrm{~min})$.

${ }^{*} \mathrm{P}$ value provided by Wald test.

†Each additional year of snus use increased the daily total exposure time by 46 min.

$\ddagger$ Each additional year of the respondent’s age decreased the daily total exposure time by $25 \mathrm{~min}$. Snus use was less common among the older respondents.

was not as significant but still detectable. The perception of snus as a harmful substance resulted in a lower total exposure time.

Several studies associate an early starting age and the amount of cigarette use with the development of substance use disorder, but only a few also link these factors with snus use. ${ }^{27} 44$ Our analyses showed a significant difference between daily and occasional snus users regarding tobacco behaviour and daily exposure to snus, suggesting that those who started using snus earlier were predisposed to daily use.

To our knowledge, only a few previous studies have attempted to quantify snus exposure and analyse predictive factors affecting use. The mean number of 10 portions per day among daily users observed in our study is in concordance with Swedish and Norwegian reports of use. ${ }^{45}$ However, on average, daily users kept snus in their mouth for only half the time of that in the study conducted by Digard et $a t^{40}$ among Swedish users.

Despite this difference, our study showed that daily snus users kept each snus dose much longer in their mouth than occasional users. The ability to tolerate long exposure times to snus in the oral mucosa increases with time and the need for a higher daily amount of snus grows as nicotine dependency develops. In their study, Fagerstöm et $a l^{39}$ concluded that Swedish snus users had developed a similar substance use disorder to smokers. Withdrawal symptoms and difficulties with refraining from use were elevated among dual users. ${ }^{47}$ Our findings support the association between the amount of use and the development of substance use disorder.
Snus use has increased and become more popular among the younger generation, while cigarette use has declined, ${ }^{4517} 48$ which may explain the narrow difference in the prevalence of snus use between the level of education also shown in Danielsson et al. ${ }^{4}$ However, respondents with an upper secondary education had a significantly lower total exposure time to snus than respondents with a comprehensive education, which is in line with recent studies assessing the association with low socioeconomic status. ${ }^{89}$ The perception of harmfulness was related to a lower exposure time, confirming health education as an effective tool for preventive interventions. This observation reinforces the common perception that education correlates with health behaviour. It would have been interesting to explore whether the socioeconomic status correlates with the prevalence or the total exposure time of use, but unfortunately, we do not have these data.

Our study showed an increased probability of snus use for ex-smokers/quitters and occasional smokers compared with non-smokers. The prevalence of shifting was almost twofold compared with the general prevalence of daily snus use (34\% vs $20 \%)$ and daily cigarette use ( $40 \%$ vs $22 \%$ ). These findings suggest that snus use can act as a gateway to start smoking. The educational background did not affect the outcome. However, the perception of smoking as very harmful to health increased the probability to shift to snus use $(\mathrm{p}<0.001)$. The threshold for switching from smoking to snus use may be reduced among occasional and former smokers because the health risks of smoking are well understood today. A common 
misconception is that snus is not that harmful and may even be regarded as a means to give up smoking. ${ }^{44}$

Daily smokers' cigarette use was more than sixfold that of occasional smokers' (mean: 13 cigarettes vs 2 cigarettes), and interestingly, they were less likely to use snus than occasional smokers. This finding may be explained by conditioning to smoking habits and the development of dependency on cigarettes. ${ }^{24}$ Dual use of snus and cigarettes was common, around $20 \%$. This may be related to availability and financial factors, that is, nicotinedependent tobacco users prefer snus but tend to switch to cigarettes when snus is unavailable due to the sales ban of snus.

Our study revealed a high total exposure to nicotine that rises concern of future health-related problems among daily nicotine-dependent users. Shifting from snus use to smoking was very common. Finland has committed to becoming nicotine free by the year 2030, and the national tobacco policy aims to decrease the prevalence of all tobacco and nicotine products. ${ }^{50}$ From this perspective, snus cannot be considered as means for harm reduction in Finland.

\section{Strengths and limitations}

The strength of our study was its ability to reach a comprehensive portion of young adult males in a military setting representing the general population because all adult Finnish males are liable for military service. Survey responses were restricted to the first week of military service to ensure responses that reflected tobacco habits before the military culture had influenced them. ${ }^{4}$

Our questionnaire design enabled a unique analysis of snus users' tobacco habits from a characterising quantitative perspective, allowing us to calculate the total amount of snus, to which a daily user is exposed. We also estimated occasional users' median snus use on those days that snus was used. Our modelling allowed analyses of predictive factors related to the total exposure time of snus use.

There are some limitations to the study design. Selfreported data on tobacco use can cause bias because people may wish to underestimate their use of tobacco products. However, several studies indicate the relatively high reliability of self-reported data. ${ }^{51-53}$ The observed low number of respondents with a basic comprehensive education may also affect the outcome. The response rate was $48 \%-60 \%$, but it was higher than $35 \%-45 \%$ usually obtained in national tobacco surveys. ${ }^{654}$

Around $30 \%$ of young men liable for military service are exempt due to suitability or health issues, creating a possible bias in our results. We can assume that the prevalence of tobacco use is likely to be even higher among these exempt individuals. For women, military service is voluntary, and approximately only $2 \%-5 \%$ of women are recruited for service. Women were therefore excluded from the results.

The nicotine content, $\mathrm{pH}$ level and quantity of snus in snus pouches vary considerably between different snus products, which affect overall exposure, and the absorption rate of nicotine and other chemicals into the bloodstream. High-nicotine snus is very popular in Finland, and this type of snus was likely used. However, the survey did not include questions concerning the nicotine content or weight of the snus pouches used. It is therefore impossible to estimate the amount of nicotine and other chemicals to which users were exposed. The availability of snus varies due to the sales ban, which is likely to somewhat affect the prevalence of snus use in Finland. Illicit snus trade is common, making the exact estimation of overall use in Finland difficult.

\section{CONCLUSIONS}

This study provides a unique quantitative analysis that characterises the total amount of snus use and exposure time to snus among young males in Finland. Our results support the vital role tobacco prevention programmes play in increasing knowledge and understanding of the harmful effects that tobacco products have on health and performance, preferably already starting in elementary school. We encourage healthcare professionals to ask about the use of any nicotine products and simultaneous use of multiple products when examining the health behaviours and tobacco habits of their patients. Studies of long-term health effects and the dependency profile of this habit are necessary.

\section{Author affiliations}

${ }^{1}$ Center for Military Medicine, Finnish Defence Forces, Helsinki, Uusimaa, Finland

${ }^{2}$ Doctoral Programme in Population Health, University of Helsinki, Helsinki, Uusimaa, Finland

${ }^{3}$ Research Unit of Oral Health Sciences, University of Oulu, Oulu, Finland

${ }^{4}$ Medical Research Center, University Hospital and University of Oulu, Oulu, Finland

${ }^{5}$ Former: Department of Cariology, Sahlgrenska Academy, University of Gothenburg, Gothenburg, Sweden

${ }^{6}$ Finnish Lung Health Association, Helsinki, Uusimaa, Finland

${ }^{7}$ The Defence Command, Finnish Defence Forces, Helsinki, Uusimaa, Finland ${ }^{8}$ Department of Infectious Disease Surveillance and Control, Finnish Institute for Health and Welfare, Helsinki, Uusimaa, Finland

${ }^{9}$ Finnish Medicines Agency Fimea, Helsinki, Uusimaa, Finland

${ }^{10}$ Division of Medicine, Department of Oncology, University of Turku, Turku, Varsinais-Suomi, Finland

${ }^{11}$ Division of Medicine, Department of Pulmonary Diseases and Clinical Allergology, University of Turku, Turku, Varsinais-Suomi, Finland

Acknowledgements The authors wish to thank the conscripts, personnel and healthcare workers of the Guard Jaeger Regiment, the Karelian Brigade, and the Kainuu Brigade for their invaluable contribution. We also wish to express our gratitude to Patrick Sandström and Miia Aro for their valuable professional observations.

Contributors All authors participated in designing the study. The acquisition of data was conducted by MD, TT, AL, SS, LP, PP and TV. The study was conducted by MD, TV, AL and SS. The first draft was prepared by MD and TT. All statistical analyses were done by MD, J0 and TT. All authors contributed to the interpretation of data, and reporting, writing and editing of the manuscript. All authors read and approved the final version of the manuscript.

Funding This study was supported by Juha Vainio Foundation (grant number N/A) and Maanpuolustuksen kannatussäätiö (grant number N/A). Open access was funded by Helsinki University Library.

Competing interests None declared.

Patient and public involvement Patients and/or the public were not involved in the design, or conduct, or reporting, or dissemination plans of this research. 
Patient consent for publication Obtained.

Ethics approval The study protocol was evaluated by the medical ethics committee of Helsinki and Uusimaa Hospital District and obtained a favourable opinion (number 148/13/03/00/2013). The Finnish Defence Forces gave their permission to perform the study. Responding to the survey was voluntary to the recruits. Each recruit was first provided with written and verbal information on the survey, whereafter they were asked to sign an informed consent document. All data were processed according to the EU General Data Protection Regulation (EU2016/679)

Provenance and peer review Not commissioned; externally peer reviewed.

Data availability statement Data are available on reasonable request. The datasets generated and/or analysed during the current study are not publicly available due to unpublished material that will be used in the future publications but are available from the corresponding author on reasonable request.

Open access This is an open access article distributed in accordance with the Creative Commons Attribution Non Commercial (CC BY-NC 4.0) license, which permits others to distribute, remix, adapt, build upon this work non-commercially, and license their derivative works on different terms, provided the original work is properly cited, appropriate credit is given, any changes made indicated, and the use is non-commercial. See: http://creativecommons.org/licenses/by-nc/4.0/.

\section{ORCID iD}

Maria Danielsson http://orcid.org/0000-0002-1555-3332

\section{REFERENCES}

1 Wackowski OA, Ray AE, Stapleton JL. Smokers' perceptions of risks and harm from snus relative to cigarettes: a latent profile analysis study. Addict Behav 2019;91:171-4.

2 Scientific Committee on Emerging and Newly Identified Health Risks (SCENIHR). Health effects of smokeless tobacco products. Brussels, Belgium: European Commission, 2008. https://ec.europa.eu/health/ ph risk/committees/04 scenihr/docs/scenihr o 013.pdf

3 World Health Organization. International agency for research on cancer. smokeless tobacco, 2018. Available: https://monographs. iarc.fr/wp-content/uploads/2018/06/mono100E-8.pdf

4 Danielsson M, Lammi A, Siitonen S, et al. Alarming development of dual snus and cigarette usage among young Finnish males. BMC Public Health 2019;19:1249.

5 Leon ME, Lugo A, Boffetta P, et al. Smokeless tobacco use in Sweden and other 17 European countries. Eur J Public Health 2016;26:817-21.

6 Finnish Institute for Health and Welfare. Tobacco statistics 2018: Finnish Institute for health and welfare, 2019. Available: https://thl.fi/ fi/tilastot-ja-data/tilastot-aiheittain/paihteet-ja-riippuvuudet/tupakka

7 Norweigan Institute of Public Health. Health risks from snus use. Oslo, Norweig: Norweigan Institute of Public Health, 2019. https:// www.fhi.no/en/publ/2019/health-risks-from-snus-use2/

8 Tjora T, Skogen JC, Sivertsen B. Increasing similarities between young adults' smoking and snus use in Norway: a study of the trends and stages of smoking and snus epidemic from 2010 to 2018. BMC Public Health 2020;20:1511.

9 Sieber AL, Jeyakumar J, Bornstein MM, et al. Swedish snuff (snus) and its effects on oral health: an update. Swiss Dent $J$ 2016;126:799-811.

10 Bhattacharyya N. Trends in the use of smokeless tobacco in United States, 2000-2010. Laryngoscope 2012;122:2175-8.

11 Delnevo CD, Wackowski OA, Giovenco DP, et al. Examining market trends in the United States smokeless tobacco use: 2005-2011. Tob Control 2014;23:107-12

12 Johnson AL, Collins LK, Villanti AC, et al. Patterns of nicotine and tobacco product use in youth and young adults in the United States, 2011-2015. Nicotine Tob Res 2018;20:S48-54.

13 Conway J. Snus tobacco sales in the United States 2008-2018: Statista, 2020. Available: https://www.statista.com/statistics/ 1094477/snus-tobacco-sales-us/\#statisticContainer

14 Directive 2001/37/EC of the European Parliament and of the Council of 5 June 2001 on the approximation of the laws, regulations and administrative provisions of the member states concerning the manufacture, presentation and sale of tobacco products 2001.

15 Rakshit SAMI. Finnish customs enforcement 2019. Finnish custom 2019.

16 Public Health Agency of Sweden. Nationella folkhälsoenkäten; Folkhäksodata. Tobaksvanor Solna, Sweden: Folkhälsomyndigheten, 2018. http://fohm-app.folkhalsomyndigheten.se/Folkhalsodata/
pxweb/sv/B_HLV/B_HLV_aLevvanor_aagLevvanortobak/ hHLV_Tobaksvanor_alder.px/?rxid=19215807-23cd-44cf-8f63b1eed980d297

17 Statistics Norway. Tobacco, alcohol and other drugs Oslo, Norway: Statistisk sentralbyrån, 2019. Available: https://www.ssb.no/en/ statbank/list/royk

18 Center for Behavioral Health Statistics and Quality. 2016 national survey on drug use and health: table 2.7B - tobacco product and alcohol use in lifetime, past year, and past month among persons aged 18 to 25: percentages, 2015 and 2016. Rockville, MD, United States: Substance Abuse and Mental Health Services Administration, 2017. https://www.samhsa.gov/data/sites/default/files/NSDUHDetTabs-2016/NSDUH-DetTabs-2016.htm\#tab2-7B

19 Lawler TS, Stanfill SB, Tran HT, et al. Chemical analysis of snus products from the United States and northern Europe. PLoS One 2020;15:e0227837.

20 Lunell E, Curvall M. Nicotine delivery and subjective effects of Swedish portion snus compared with $4 \mathrm{Mg}$ nicotine polacrilex chewing gum. Nicotine Tob Res 2011;13:573-8.

21 Pickworth WB, Rosenberry ZR, Gold W, et al. Nicotine absorption from smokeless tobacco modified to adjust $\mathrm{pH}$. J Addict Res Ther 2014;5:1000184.

22 Rostron BL, Chang CM, van Bemmel DM, et al. Nicotine and toxicant exposure among U.S. smokeless tobacco users: results from 1999 to 2012 National health and nutrition examination survey data. Cancer Epidemiol Biomarkers Prev 2015;24:1829-37.

23 Services. USDoHaH. Preventing tobacco use among youth and young adults: a report of the surgeon General. Atlanta (GA), United States: Department of Health and Human Services CfDCaP, National Center for Chronic Disease Prevention, and Health Promotion OoSaH, 2012.

24 Benowitz NL. Nicotine addiction. N Engl J Med Overseas Ed 2010;362:2295-303.

25 Benowitz NL, Hukkanen J, Jacob P. Nicotine chemistry, metabolism, kinetics and biomarkers. Handb Exp Pharmacol 2009;192:29-60.

26 Nordenstam F, Lundell B, Edstedt Bonamy A-K, et al. Snus users had high levels of nicotine, cotinine and 3-hydroxycotinine in their breastmilk, and the clearance was slower than in smoking mothers. Acta Paediatr 2019;108:1250-5.

27 Siqueira LM, COMMITTEE ON SUBSTANCE USE AND PREVENTION. Nicotine and tobacco as substances of abuse in children and adolescents. Pediatrics 2017;139:e20163436.

28 Piano MR, Benowitz NL, FitzGerald GA, et al. Impact of smokeless tobacco products on cardiovascular disease: implications for policy, prevention, and treatment. Circulation 2010;122:1520-44.

29 Boffetta P, Straif K. Use of smokeless tobacco and risk of myocardial infarction and stroke: systematic review with meta-analysis. BMJ 2009;339:b3060.

30 Aro P, Ronkainen J, Storskrubb T, et al. Use of tobacco products and gastrointestinal morbidity: an endoscopic population-based study (the Kalixanda study). Eur J Epidemiol 2010;25:741-50.

31 Luo J, Ye W, Zendehdel K, et al. Oral use of Swedish moist snuff (snus) and risk for cancer of the mouth, lung, and pancreas in male construction workers: a retrospective cohort study. Lancet 2007;369:2015-20.

32 Skaug E-A, Nes B, Aspenes ST, et al. Non-Smoking tobacco affects endothelial function in healthy men in one of the largest health studies ever performed; the Nord-Trøndelag health study in Norway; HUNT3. PLoS One 2016;11:e0160205.

33 Gupta R, Gupta S, Sharma S, et al. Risk of coronary heart disease among smokeless tobacco users: results of systematic review and meta-analysis of global data. Nicotine Tob Res 2019;21:25-31.

34 Øverland S, Skogen JC, Lissner L, et al. Snus use and cardiovascular risk factors in the general population: the HUNT3 study. Addiction 2013;108:2019-28.

35 Carlsson S, Andersson T, Araghi M, et al. Smokeless tobacco (snus) is associated with an increased risk of type 2 diabetes: results from five pooled cohorts. J Intern Med 2017;281:398-406.

36 Wilson KM, Markt SC, Fang F, et al. Snus use, smoking and survival among prostate cancer patients. Int J Cancer 2016;139:2753-9.

37 Baba S, Wikström A-K, Stephansson O, et al. Influence of snuff and smoking habits in early pregnancy on risks for stillbirth and early neonatal mortality. Nicotine Tob Res 2014;16:78-83.

38 Byhamre ML, Araghi M, Alfredsson L, et al. Swedish snus use is associated with mortality: a pooled analysis of eight prospective studies. Int J Epidemiol 2021;49:2041-50.

39 Fagerstrom K. A comparison of dependence across different types of nicotine containing products and coffee. Int J Environ Res Public Health 2018;15:1609.

40 Digard H, Errington G, Richter A, et al. Patterns and behaviors of snus consumption in Sweden. Nicotine Tob Res 2009;11:1175-81. 
41 Digard H, Proctor C, Kulasekaran A, et al. Determination of nicotine absorption from multiple tobacco products and nicotine gum. Nicotine Tob Res 2013;15:255-61.

42 Schafer JL, Graham JW. Missing data: our view of the state of the art. Psychol Methods 2002;7:147-77.

43 van Buuren S. Multiple imputation of discrete and continuous data by fully conditional specification. Stat Methods Med Res 2007:16:219-42.

44 Grøtvedt L, Forsén L, Ariansen I, et al. Impact of snus use in teenage boys on tobacco use in young adulthood; a cohort from the HUNT study Norway. BMC Public Health 2019;19:1265.

45 Lund KE, Vedøy TF. Utbredelse AV snus I Norge Norge: Folkhelseinstituttet, 2018. Available: https://www.fhi.no/nettpub/ tobakkinorge/bruk-av-tobakk/utbredelse-av-snus-i-norge/

46 Elisabeth K. Tobakk I Norge 2018. Folkehelseinstituttet, 2019.

47 Post A, Gilljam H, Rosendahl I, et al. Symptoms of nicotine dependence in a cohort of Swedish youths: a comparison between smokers, smokeless tobacco users and dual tobacco users. Addiction 2010;105:740-6.

48 Lund KE, Vedøy TF, Bauld L. Do never smokers make up an increasing share of snus users as cigarette smoking declines? Changes in smoking status among male snus users in Norway 2003 15. Addiction 2017;112:340-8.
49 Ruokolainen O, Ollila H, Lahti J, et al. Intergenerational social mobility, smoking and smokeless tobacco (snus) use among adolescents during 2008-2017. Addict Behav 2019;98:106022.

502030 T-fF. Tobacco act, 2020. Available: https://savutonsuomi.fi/ en/towards-tobacco-free-finland/tobacco-act/ [Accessed 16 Jun 2021].

51 Caraballo RS, Giovino GA, Pechacek TF, et al. Factors associated with discrepancies between self-reports on cigarette smoking and measured serum cotinine levels among persons aged 17 years or older: third National health and nutrition examination survey, 19881994. Am J Epidemiol 2001;153:807-14.

52 Huerta M, Chodick G, Balicer RD, et al. Reliability of self-reported smoking history and age at initial tobacco use. Prev Med 2005;41:646-50.

53 Boykan R, Messina CR, Chateau G, et al. Self-Reported use of tobacco, e-cigarettes, and marijuana versus urinary biomarkers. Pediatrics 2019;143:e20183531.

54 Kinnunen JM, Pere LA, Raisamo S. The Adolescent Health and Lifestyle Survey 2017:Adolescent smoking, alcohol use and gambling. Helsinki, Finland: Ministry of Social Affairs and Health, 2017: 108. 